\title{
Obstacles Facing Saudi Exporters of Non-Oil Products
}

\section{Mohammed Duliem Al-Qahtany*}

\begin{abstract}
This study explores the obstacles facing Saudi exporters of non-oil products. The sampling frame comprised 411 firms, which have been involved in exporting for at least two years as identified by the Saudi Export Development Center. The research has investigated twenty five obstacles that have some relation to non-oil export products. Competition with foreign firms was found to be the first obstacle with the highest mean of (3.212) followed by lack of information about potential export markets with a mean of (2.887). Moreover, with regard to the ways Saudi exporters might overcome these obstacles, the investigations suggested to Saudi exporting firms fifteen factors that might improve Saudi non-oil exporting products.
\end{abstract}

\section{Introduction}

For many organisations, exports are a necessary part of their business operations. Without exports, local production cannot reach overseas markets and this will negatively affect domestic income. Exports increase the rate of economic development and thereby help the government achieve its objectives.

Export diversification is one of the most important objectives that Saudi Arabia seeks to achieve. Saudi Arabia is seeking to decrease its dependence on crude oil as the main source of income (Saudi Export Directory, 1996). Saudi Arabia has become a main center of exports in the area. This has led to competition among exporters to win, satisfy and compete in the global marketplace. Therefore it is important to identify the factors that may affect export success, especially when there has been a lack of empirical research at the firm level.

This article comes up with the following problems: little share of Saudi non-oil products, little confidence from Saudi exporters, no clear vision for the exporters, lacking abilities to enter other markets, Saudi non-oil precuts cannot compete with foreign products. Therefore this study will try to help avoid the obstacles and difficulties facing the sector of exporters, to help governmental establishments participate in solving the problems, and to support Saudi exporters to meet the needs of targeted markets.

\footnotetext{
* Assistant Professor of International Management, College of Management Science and Planning, King Faisal University.
} 
130 The Lahore Journal of Economics, Vol.6, No.1

The main objective of this study is to find out what obstacles, if any, face Saudi exporters, and to suggest ways in which such obstacles can be overcome. For the purposes of this study, non-oil products are any products other than crude oil and firms are classified as successful or less successful exporters, based on the measurement of export performance.

\section{Literature Review}

Table 1 indicates the values and quantities of Saudi non-oil exports between year 1995 and year 1999 to the world markets. Table 1 shows the increase and decrease of the quantities of Saudi non-oil products.

Table-1: Non-oil Saudi's Exports to the World Markets

\begin{tabular}{lcc}
\hline Year & Value in Million & Qty. in 1000 tonnes \\
\hline $\mathbf{1 9 9 5}$ & 6052 & 199834 \\
$\mathbf{1 9 9 6}$ & 6863 & 228634 \\
$\mathbf{1 9 9 7}$ & 6755 & 214893 \\
$\mathbf{1 9 9 8}$ & 5798 & 278901 \\
$\mathbf{1 9 9 9}$ & 5332 & 175449 \\
\hline
\end{tabular}

Certain decisions need special care when managers are setting up an exporting system, particularly the choice of country (Deresky, 1994). Saudi non-oil exporters have missed the opportunity of an Arab free trade area agreement that give all Arab products 40 per cent discount of customs tariffs when entering any of the Arab countries. However Table 2 shows illogical exporting movement, the highest percentage was for United Arab Emirates and the second country was the United States. Jordan and Egypt were the lowest.

Table-2: 1999 Saudi Non-oil Exports by Major Countries

\begin{tabular}{lcr}
\hline \multicolumn{1}{c}{ Country } & Value US\$ Million & \% \\
\hline United Arab Emirates & 762 & 14.3 \\
United States & 489 & 9.2 \\
Kuwait & 452 & 8.5 \\
India & 244 & 4.6 \\
Hong Kong & 235 & 4.4 \\
Bahrain & 211 & 3.9 \\
Egypt & 198 & 3.7 \\
Japan & 197 & 3.7 \\
Singapore & 144 & 2.7 \\
Jordan & 141 & 2.6 \\
Rest of the world & 2259 & 42.2 \\
\multicolumn{1}{c}{ Total } & 5332 & 100 \\
\hline
\end{tabular}


While much has been said about the relationship between size and export involvement, there appears to be a lack of empirical evidence to indicate the obstacles facing Saudi exporters and the assistance requirements Saudi exporters need to overcome these barriers.

Saudi exporters, like exporters in most countries, may face two different types of barriers, internal or external. Although the export operation from Saudi Arabia abroad does not involve many administrative procedures, some exporters have commented about the delay caused by such procedures in relation to the seaports, commercial banks and the custom organisation (Saudi Chambers' Council, 1994).

Most Saudi exporters are newly engaged in export activity and as such they lack information about international markets and the regulations procedures in the markets (Saudi Chambers' Council, 1992; Al-Aaktassiad wal aamal, 1994; Saudi Chambers' Council, 1994; Almajalla, 1994).

Finance and insurance risks are another form of internal barrier encountered by Saudi exporters, especially small exporters and the local commercial banks are reluctant to give guarantees to them. Other exporters lack insurance cover against export risks (Saudi Chambers' Council, 1992; Al-Aaktassiad wal aamal, 1994; Saudi Chambers' Council, 1994).

Although the location of Saudi Arabia is strategic, the cost of transportation from Saudi Arabia to overseas markets is considered high compared to other countries' transportation costs. (Saudi Chambers' Council, 1992; Al-Aaktassiad wal aamal, 1994; Saudi Chambers' Council, 1994; AlEqtisadiah, 1994; Tegart Al Riyadh, 1996). Seaport taxes are considered another barrier for Saudi exporters (Al-Aaktassiad wal aamal, 1994; Al-Eqtisadiah, 1994).

\section{External Barriers}

High customs taxes in other countries are one of the important external barriers that are used to protect their local production. A1-Aali (1995), discovered that obstacles facing Saudi exporters were: variations in product standardisation; high competition in overseas markets; cost of importing material; lack of information about overseas markets; changes in foreign currency and cost export customs. This finding can not be generalised, because Al-Aali's study concentrated on only two types of industry, chemicals and food. However, the type of obstacles faced could be determined by the type of industry. Also, the findings of this research carried out in Saudi Arabia show that exporters face organisational, financial, production and marketing obstacles. 
Arguably, there are no major differences between the barriers facing Saudi exporters and those faced by exporters from other developing countries. In Turkey, for example, Bodur (1986) shows the difference in the type of obstacles faced by two different types of exporters.

\section{Factors Connected with Export Success}

Based on the success factors associated with Canadian firms, Kamath et al (1987) consider four crucial factors for export success:

1. The fundamental strength of having good people at both the managerial and work force levels;

2. A clear philosophy and corporate mission;

3. Action skills leading to good implementation of company strategy;

4. Close attention to the specifics of company's exporting situation and activity (a market - by - market, product by product, or contract by contract approach to business).

The degree of success of Japanese firms in international markets compared to the American and British has led to the question: what are the factors contributing to the success of Japanese firms? Kotler and Fahey (1982) state understanding and use of marketing has played a major role for Japanese success in the international market.

Another form of success that helped the Japanese to break down the American and British stronghold in Saudi Arabia is highlighted by Yavas et al (1987: 242) as follows:

"Careful product design to suit local needs, better value for money, timely delivery, long-term dependability, and the meticulous attention given to after-sales services. Having local repair facilities, spare parts, and adequate warranties are extremely important to Saudi customers. The Japanese are sensitive to this need to the extent that they have employed traveling clinics with factor-trained technicians in Saudi Arabia, in addition to permanent facilities."

There are several factors that are motivating firms to become exporters. However, firms may also face obstacles to their export operations, and in this section we will discuss the barriers that exporters might encounter. 
While much has been said about the relationship between size and export involvement, there appears to be a lack of empirical evidence to indicate the obstacles facing Saudi exporters and the assistance requirements Saudi exporters require to overcome these barriers.

Saudi exporters, like exporters in most countries, may face two different types of barriers, internal or external. The former are the local barriers which are related to the internal procedures and regulations; these to some extent are controllable. The latter are related to the importing countries, such as the import procedures and regulations, which are to some extent uncontrollable.

Although the export operation from Saudi Arabia abroad does not involve many administrative procedures, some exporters have commented about the delay caused by such procedures in relation to the seaports, commercial banks and the custom organisation (Saudi Chambers' Council, 1994).

Also, the lack of international market information is another internal barrier. Most Saudi exporters are newly engaged in export activity and as such they lack information about international markets and the regulation procedures in these markets (Saudi Chambers' Council, 1992; Al-Aaktassiad wal aamal, 1994; Saudi Chambers' Council, 1994; Almajalla, 1994).

A1-Aali (1995) indicates that high customs taxes in other countries are one of the important external barriers that are used to protect their local production. He also indicates that in view of the relatively poor Saudi experience in exporting, Saudi exporters face high competition in international markets from more experienced firms.

\section{Method}

\section{The Questionnaire}

A questionnaire was used to collect the required data partly because of practical effectiveness. In this respect, Clover and Basley (1979) indicated that prospective respondents can be reached at a relatively low cost by the use of a questionnaire and a quick turnaround time can usually be expected. During the planning stage, it was felt that there were very few reliable research studies and little information about obstacles Saudi exporters faced for non-oil products. Therefore, it became evident that the information needed for this research could best be obtained through a mail questionnaire filled in by the marketing or executive managers. According to Sellitez et al (1960), questionnaires are especially beneficial to a researcher who seeks information about the internal operations of an organisation. As Mason and Bramble (1978) and Caswell (1989) suggest, a questionnaire has 
the advantage of increasing the generalisation of data, and at the same time gives the respondents freedom to express their points of view.

The questionnaire was designed to ensure that respondents followed precise specified instructions. The questionnaire was divided into sections informing the respondents of the nature of the information requested. This was done in order to provide motivation for the respondents to continue and avoid monotony in completing the questionnaire. The questionnaire did not request any form of personal identification that may have inconvenienced the respondents and jeopardised anonymity. It was felt that such measures would eliminate any threat to the participants that might cause bias in their responses.

\section{Describing the Sample}

Previous research studies conducted in Saudi Arabia reported major difficulties in obtaining information from Saudi manufacturing firms. The problem is that most Saudi firms are not accustomed to the idea of externally conducted surveys. Many enterprises fear that the release of information about their activities will benefit competitors. Consequently, attempts to investigate Saudi firms have always encountered difficulties: no survey of the type proposed here has therefore been carried out without complications in Saudi Arabia in the past. It was therefore decided that it was necessary to obtain responses from 411 exporting firms that have at least two years of export experience in order to have a reasonable basis for statistical analysis. The data collection process was implemented during the months of Sept to Nov 1998.

The researcher faced difficulties with the respondents. Owing to the poor quality of the postal service, some firms did not receive the questionnaire, and in some cases the researcher had to deliver it by hand. Some people thought the questionnaire a waste of time because they did not recognise the importance of such research to their export development. By the middle of November 1998, which was the cut-off date, 108 questionnaires had been returned, of which nine were unusable, leaving 99 usable responses. The response rate was, therefore, 24 per cent, which was considered to be an acceptable response rate.

\section{Details of Respondents}

The respondents from non-oil exporters, type of industry, number of export market, years of starting exporting, years of experience, and size of firm are shown in Table 3. 
Table-3: Social Data and Business Classification -- Total Sample

Exporting Firms

\section{Type of Industry:}

Textile, leather and paper products

Furniture

Animal and farm products

Chemical products

$5 \quad 5.0 \%$

Plastic products

$3 \quad 3.0 \%$

$3 \quad 3.0 \%$

Food and beverages

$14.1 \%$

$16.2 \%$

Mineral products

$10.1 \%$

Building materials

$18 \quad 18.2 \%$

Engineering and electric products

$17.2 \%$

Other products

$9 \quad 9.1 \%$

Number of export markets:

$1-6$

More than six countries

Years of exporting:

Less export experience

More export experience

Years of Experience:

Less experience

More experience

Size of Firm:

Small

Medium

Large

$4 \quad 4.0 \%$

$51 \quad 51.5 \%$

$48 \quad 48.5 \%$

$45 \quad 45.0 \%$

$54 \quad 55.0 \%$

$49 \quad 49.0 \%$

$50 \quad 51.0 \%$

$29 \quad 29.0 \%$

$50 \quad 51.0 \%$

$20 \quad 20.0 \%$

The target population of this study is all non-oil producing exporting firms in Saudi Arabia. The source of information about the target population is the Saudi Export Directory (1995) that is published by the Saudi Export Development Center. Respondents included all types of non-oil industry, which was considered as giving the respondents greater expertise in their different fields and therefore would have a better understanding of the use of questionnaires in the field of research. Number of export markets was assumed to play an important and significant role in dividing the type of strategy (either concentration strategy or diversification strategy). It was assumed that years of starting export would be a strong influence on the responses to the questionnaires.

Experience is a major factor in firms' positions. Therefore, it was assumed that experience would be valuable for a research study because firms would have gained knowledge that would benefit the research and contribute to the subject matter of this study. The firms were identified as 
136 The Lahore Journal of Economics, Vol.6, No.1

being either small, medium or large size according to the number of employees.

\section{Questionnaire Analysis}

All data were keypunched, verified, and computerised in order to produce the highest attainable level of accuracy. The questionnaires were edited and coded, using a COBOL coding form for the purpose of computer processing. The analysis was carried out on a personal computer, using the Statistical Package for the Social Sciences Extended Programme package (SPSS-X).

\section{Results}

Table 4 presents a list of 25 obstacles facing Saudi exporters. Respondents were asked to rate these obstacles on a five-point scale (0-4). Mean scores were calculated for each item. The items are presented in Table 2 in rank order, based on the mean.

The first obstacle, competition with foreign firms in export markets, gave the highest mean, 3.212. This was followed by lack of information about potential export markets with a mean of 2.887, and dumping strategy in some export markets, with a mean of 2.856. However, the fourth and the fifth obstacles facing Saudi exports, which are increasing tariffs in other countries and restrictions in importing countries, could be classified as external economic barriers; they are to some extent uncontrollable. These are the five most important obstacles facing Saudi exporters.

Table-4: The Obstacles Facing Saudi Exporters

\begin{tabular}{lc}
\hline \multicolumn{1}{c}{ Obstacles to Saudi Exporting } & The Mean \\
\hline Competition with foreign firms in export markets & 3.212 \\
Lack of information about potential export markets & 2.887 \\
Dumping strategy in some export markets & 2.856 \\
Increasing tariffs in other countries & 2.808 \\
Restrictions in importing countries & 2.763 \\
Unclear trade agreement with other countries & 2.740 \\
Cost of importing raw material & 2.677 \\
Lack of the right personnel involved in exports & 2.649 \\
High transportation cost out of S.A & 2.531 \\
\hline
\end{tabular}


Lack of experience in exporting 2.500

Supplying services in foreign markets

High cost of Saudi seaports

Differences in product standards

Complex export procedures

Insufficient companies specialising in export

Cost of intermediate local products

Obstacles related to Saudi seaports

Unfamiliarity with export documents \& licenses, shipping and procedures

High transportation cost in S.A

High standard requirement of technology in the industry

Difficulties in finance from international markets

Cost of labour in S.A

Insufficient production capacity to meet foreign demand

Lack of insurance cover

Differences in exchanging currency

1.660

Moreover, with regard to how Saudi exporters might overcome these obstacles, the investigations suggested fifteen factors to the firms which might improve Saudi exporting. Table 5 shows these factors and how important each one is to improving Saudi exports, in the perception of the respondents. These factors are ranked in order of the means depending on the firms' responses.

The items rated most highly by respondents were that of giving more discounts to exporters for transportation and loading, establishing an up-to-date computer information system to provide the exporter with information about any international market, incentive agreement with other countries for exemption from customs duties, greater support for exporters from the Saudi embassies and speeding up export procedures.

From these responses, it can be seen that even though the Saudi government gives some incentives to Saudi exporters, exporting firms are still looking for more support from the government and this opens up areas for debate which should be covered by another study. 
138 The Lahore Journal of Economics, Vol.6, No.1

Table-5: Factors which may Improve Saudi Exports

Factors which may improve Saudi Exports

The Mean

Give more discounts to exporters for transportation and loading

3.535

Establish up-to-date computer information system to provide

3.505

exporters with information about any international markets

Incentive agreement with other countries for custom exemptions

3.465

The S.A. embassies should be more active in supporting

3.367

exporters

The procedure of export should be faster

3.323

Support the organisations responsible for exports

3.260

Give exporters a special price to exhibit their products abroad

3.250

Reduce the customs duties on import of intermediate products

for exporters

Special price from SABIC companies to exporter firms

3.205

Establish special bank to support exporters in their operations

(especially new exporter)

Allow new exporters to exhibit their products abroad, free of charge

Give subsidy to exporters

Establish special companies responsible for export activities

Special price for exporters when they bring labour into Saudi Arabia

Encourage overseas companies to invest in Saudi Arabia

2.368

Approximately 48 per cent of the firms (successful exporters) carried out market research before taking an export decision, while about 10 percent of the firms did not undertake market research before taking an export decision. In the other group (1ess successful exporters), 25.8 per cent of the firms carried out market research before taking an export decision. However, 15.7 per cent of the firms did not carry out market research before they took an export decision.

In measuring export success by the export ratio, it was found that approximately 21 per cent of the firms (successful exporters) had a separate export department to handle export activities while 27.6 per cent did not. On the other hand, of the less successful exporters, 14.3 per cent of the firms had a separate export department while 36.7 per cent of them did not. 


\section{Summary and Recommendations}

The importance of exports in contributing towards economic growth is widely recognised in Saudi Arabia. However, there has been a lack of empirical research at the firm level. The study, therefore, is a contribution to define the obstacles Saudi exporters face of non-oil products. Furthermore, this study provides new information on the export behaviour and performance of non-oil producing firms in Saudi Arabia; and suggests fifteen factors that might improve Saudi Exports.

According to the firms' respondents, the major obstacles faced by Saudi exports are: competition with foreign firms in export markets; lack of information on potential export markets; and dumping strategy in some export markets. These three barriers can be classified as marketing obstacles, and are to some extent controllable. The fourth and fifth obstacles are increasing tariffs in other countries and restrictions in importing countries; these can be classified as external barriers and are to some extent uncontrollable. The above barriers are the five most important obstacles faced by Saudi exporters.

A number of factors were suggested to firms that may improve Saudi exports and overcome such obstacles. The most important five factors, in the perception of respondents, are as follows: giving more discounts to exporters for loading and transportation, establishing an upto-date computer information system to provide exporters with information about the international market; incentive agreements with other countries for custom exemption; Saudi Arabian embassies being more active in supporting exporters; and, finally expediting the procedure for export in Saudi Arabia.

Further some firms complained about the high electricity connection fees; therefore, the investigation suggests special electricity connection fees for export firms may be adopted.

Although the Ministry of Industry has provided some incentives for Saudi firms, Saudi exporters are still looking for more support from the Ministry of Industry and other related ministries and agencies. Their main needs could be met by:

- Establishing a new organisation that has executive authority. Such an organisation should be linked (at a high level) with the Saudi government to be responsible for export activities. 
140 The Lahore Journal of Economics, Vol.6, No.1

- Granting more discounts to exporters for loading and transportation (allowing for W'TO regulations).

- Establishing an up-to-date computer information system to provide exporters with information about any international market.

- Arranging incentive agreements with other countries for custom exemptions, to arrange an open market between these countries. This would be a task for the Trade Ministry.

- Speeding up export procedures in Saudi Arabia and better linkage with embassies.

- Introducing special electricity connection fees for exporting firms.

- Co-operation between firms, that produce similar products, to import raw material via one order, from the same supplier, instead of ordering them individually, to reduce costs. 


\section{References}

A1-Aali, A., 1995, "Obstacles Facing Saudi Arabian Food and Chemical Exporters", International Journal of Commerce and Management, Vol. 5, No. 3, pp. 17-31.

A1-Eqtisadiah, 1994, "Seven Major Obstacles Facing Saudi Company Exports”, Al-Eqtisadiah, The International Arab Business Daily, No. 437, 24/5/1994 (Arabic).

A1-1ktissad Wal-Aamal, September 1994, "The Saudi Export Start Movement" Al-ktissad - Wal-Aamal Arab Business Magazine Special Issue/Saudi Export (Arabic).

A1-Majalla, 1994, "Lack of Incentives, Financing and Information are Obstacles to Export" Al-Majalla, No. 768, pp. 56-58. 5-11-1994 (Arabic).

Bodur, M., 1986, "A Study of the Nature and Intensity of Problems Experienced by Turkish Exporting Firms" In Cavusgil, S.T.(Ed)' Advances In International Marketing, Vol. 1, pp. 205-232.

Caudron, S., 1991, 'Training Ensures Success Overseas', Personnel Journal, 70 (12): $27-30$.

Deresky, H., 1994, International Management: Managing Across Borders and Cultures, New York: Harper Collins, p. 133.

Kamath, S., Rosson, P.J., Patton, D. and Brooks, M., 1987, "Research on Success in Exporting: Past, Present, and Future”, in Rosson, P.J., and Reid, S.D., Eds, Managing Export Entry and Expansion: Concept and Practice, Praeger: New York.

Kotler, P. and Fahey, L., 1982, “The World's Champion Marketers: The Japanese", The Journal of Business Strategy, Summer, pp.3-13.

Mason, E. and Bramble, W., 1978, Understanding Conducting Research: Application in Education and Behavior Sciences, New York: McGraw-Hill.

Sellifez, C. et al, 1960, Research Method in Social Relations, New York: Holy. 
142 The Lahore Journal of Economics, Vol.6, No.1

Saudi Chambers' Council (12-13) January, 1992, “The Services' Role to Encourage Saudi Export”, Saudi Chambers Council, Conference about Saudi Export Development, in Jeddah, Saudi Arabia.

Saudi Chambers' Council, 1994, Export Development Center. Press, Riyadh, Saudi Arabia.

Saudi Export Directory, 1996, 3rd Edition, Saudi Export Development Center, Riyadh.

Tegart A1-Riyadh, 1996, "Producing for Exporting is Our First Choice", Tegart Al-Riyadh, No. 400, January 1996, pp. 18-24 (Arabic).

Yavas, U., Cavusgil, S.T. and Tuncalp, C., 1987, “Assessment of Selected Foreign Suppliers by Saudi Importers: Implications for Exporters”, Journal of Business Research, Vol. 15, pp. 237-346. 